\title{
Patients With High-Cost Chronic Conditions Rely Heavily on Primary Care Physicians
}

\author{
Manisha A. Sharma, MD, Newton Cheng, MS, Miranda Moore, PhD, \\ Megan Coffman, MS, and Andrew W. Bazemore, MD, MPH
}

Today's US physician workforce principally comprises specialists trained in the care of specific chronic conditions in the outpatient setting. However, a majority of patients seeking care for most of 14 highcost chronic conditions, for example hypertension, were more likely to see a primary care physician than a specialist physician (69\% vs. 24\%, respectively). (J Am Board Fam Med 2014;27:11-12.)

Keywords: Physician-Patient Relations, Quality of Health Care

Approximately $70 \%$ of US physicians report subspecialty training in the care of groups with specific diseases. One might infer that much of the care for these conditions would take place in a specialty outpatient setting. To test this assumption, outpatient physician visits in the National Ambulatory Medical Care Survey (2008) were reviewed for reports of care provided for each of the 14 highestcost chronic conditions listed in the Center for Medicare \& Medicaid Services Chronic Conditions Dashboard. ${ }^{1}$ The conditions identified were linked to applicable International Classification of Diseases, Ninth Revision, codes as outlined in the Center for Medicare \& Medicaid Services chronic disease database. For most conditions listed, a higher proportion of the outpatient visits were to primary care physicians - those in family medicine, general practice, internal medicine, and pediatrics.

This article was externally peer reviewed.

Submitted 23 April 2013; revised 24 July 2013; accepted 5 August 2013.

From the Evergreen Health Cooperative, Baltimore, MD (MAS); the Robert Graham Center for Policy Studies in Family Medicine and Primary Care, Washington, DC (NC, $\mathrm{MM}, \mathrm{MC}, \mathrm{AWB})$.

Funding: none.

Conflict of interest: none declared.

Corresponding author: Manisha Sharma, MD, Evergreen Health Cooperative, 3000 Falls Rd, Baltimore, MD, 21211 (E-mail: manishaim@aol.com).

\footnotetext{
See Related Commentary on Page 6.
}

Primary care has been acknowledged as essential to the success of health care reform and the nation's triple aim. ${ }^{2}$ However, the degree to which primary care physicians are depended on by an increasingly chronically ill US population may not be fully appreciated. ${ }^{3}$ Ostbye and colleagues ${ }^{4}$ show that primary care physicians hoping to meet current clinical guideline recommendations for patients with chronic conditions such as diabetes and hypertension would need an average of 10.6 hours per working day to care for each patient with multiple chronic conditions. Primary care physicians might be referred to as "complex care physicians," particularly considering that they also are charged with identifying patient needs, offering preventive services, coordinating with community and public health resources, and facilitating behavior change.

\section{References}

1. Centers for Medicare and Medicaid Services. Interactive CMS data. Available from: http://www. ccwdata.org/business-intelligence/chronic-conditions/ index.htm/. Accessed February 20, 2013.

2. Berwick DM, Nolan TW, Whittington J. The triple aim: care, health and cost. Health Aff (Millwood) 2008;27:759-69.

3. Fortin M, Soubhi H, Hudon C, Bayliss EA, van den Akkar M. Multimorbidity's many challenges. BMJ 2007;334:1016-7.

4. Ostbye T, Yarnall KS, Krause KM, Pollak KI, Gradison M, Michener JL. Is there time for management of patients with chronic disease in primary care? Ann Fam Med 2005;3:209-14. 
Figure 1. Number and percentage of outpatient chronic condition visits by physician type in the past year, based on the 2008 National Ambulatory Medical Care Survey. ${ }^{*} P<0.05$ significant test done by SAS Procedure Surveyfreq Roa-Scott $\chi^{2}$ test. COPD, chronic obstructive pulmonary disease.

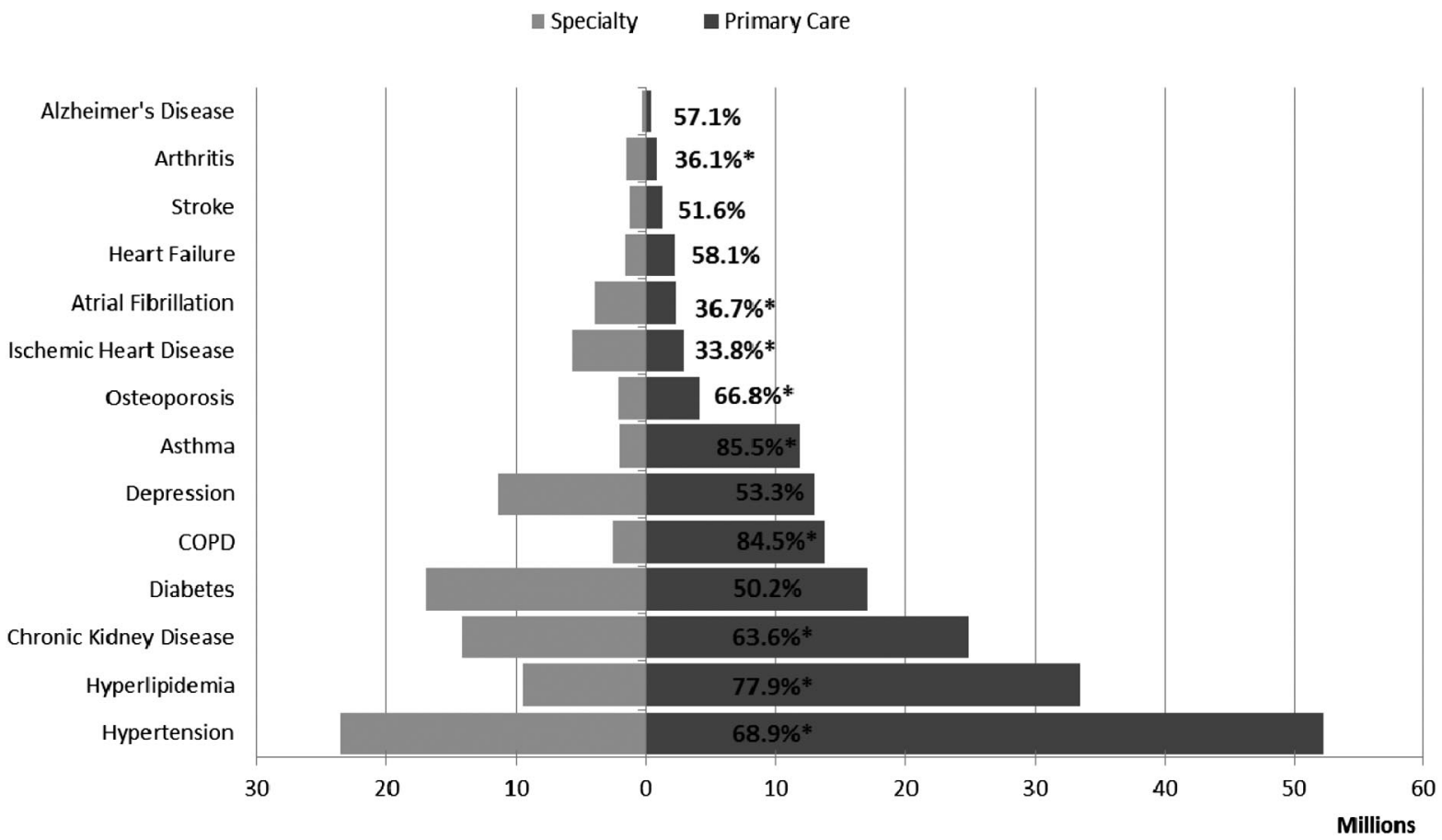

